\title{
INDOOR MODELLING BENCHMARK FOR 3D GEOMETRY EXTRACTION
}

\author{
Charles Thomson* \& Jan Boehm
}

\author{
Dept. of Civil, Environmental \& Geomatic Engineering (CEGE), \\ University College London, Gower Street, London, WC1E 6BT, UK \\ charles.thomson.11@ucl.ac.uk; j.boehm@ucl.ac.uk
}

\author{
Commission V, WG V/4
}

KEY WORDS: Indoor, 3D Modelling, Benchmark, Terrestrial Laser Scanning, Segmentation, Reconstruction

\begin{abstract}
:
A combination of faster, cheaper and more accurate hardware, more sophisticated software, and greater industry acceptance have all laid the foundations for an increased desire for accurate 3D parametric models of buildings. Pointclouds are the data source of choice currently with static terrestrial laser scanning the predominant tool for large, dense volume measurement. The current importance of pointclouds as the primary source of real world representation is endorsed by CAD software vendor acquisitions of pointcloud engines in 2011. Both the capture and modelling of indoor environments require great effort in time by the operator (and therefore cost). Automation is seen as a way to aid this by reducing the workload of the user and some commercial packages have appeared that provide automation to some degree. In the data capture phase, advances in indoor mobile mapping systems are speeding up the process, albeit currently with a reduction in accuracy. As a result this paper presents freely accessible pointcloud datasets of two typical areas of a building each captured with two different capture methods and each with an accurate wholly manually created model. These datasets are provided as a benchmark for the research community to gauge the performance and improvements of various techniques for indoor geometry extraction. With this in mind, non-proprietary, interoperable formats are provided such as E57 for the scans and IFC for the reference model. The datasets can be found at: http://indoor-bench.github.io/indoor-bench
\end{abstract}

\section{INTRODUCTION}

\subsection{Motivation}

The need for 3D models of buildings has gained increased momentum in the past few years with the increased accuracy and reduced cost of instrumentation to capture the initial measurements. This tied with more sophisticated geometric modelling tools to create the digitised representation has helped smooth the process. Alongside this, the concurrent development of Building Information Modelling (BIM) worldwide has created demand for accurate $3 \mathrm{D}$ models of both exterior and interior of assets throughout their lifecycle. This is due to a key component of BIM being a data-rich 3D parametric model that holds both geometric and semantic information.

Generally, digital modelling is carried out to provide a representation or simulation of an entity that does not exist in reality. However Geomatics seeks to model entities as they exist in reality. Currently the process is very much a manual one and recognised by many as being time-consuming, tedious, subjective and requiring skill (Rajala and Penttilä, 2006; Tang et al., 2010).

Human intuition provides the most comprehensive understanding of the complex scenes presented in most indoor environments, especially when adding rich semantic information as required for BIM to be effective. However with the continuing development of capture devices and modelling algorithms, driven by the increased need for indoor models, it is felt that a common benchmark dataset is required that represents the status quo of capture, allowing different geometry extraction methods to be tested against it as they are developed.

\subsection{Indoor Geometry Extraction}

Geomatics has a track record in geometry recovery with reconstruction from terrestrial data of facades (Schmittwilken and Plümer, 2010), pipe work (Kawashima et al., 2011) and also from aerial LIDAR data ( $\mathrm{Pu}$ and Vosselman, 2009; Tao, 2005). However Nagel et al. (2009) points out that the full automatic reconstruction of building models has been a topic of research for many groups over the last 25 years with little success to date.

That said changes in capture requirements and improvements in technology have pushed the focus onto interior reconstruction. That focus has mainly been on the use of computational geometry algorithms to extract the 3D representation of building elements, including surface normal approaches (Barnea and Filin, 2013), plane sweeping (Budroni and Boehm, 2010) and region growing (Adan and Huber, 2011).

Laser scanners can naturally only measure visible surfaces and surface-based reconstructions have been common as above. However the 3D parametric model at the heart of BIM requires the production of volumetric geometry, therefore approaches based on voxels have been advanced, such as the reconstruction of the indoor environment from (Oesau et al., 2014) who use space partitioning, labelling and graph-cut to reconstruct geometry. It should be noted that all these methods only

\footnotetext{
${ }^{*}$ Corresponding author
} 
construct simple CAD geometry and not parametric geometry as would be required for BIM.

Due to the activity in this field two review papers have been written summarising the state of reconstruction research into automated geometry reconstruction for buildings. Tang et al. (2010) comprehensively reviews the area of geometry generation for BIM from laser scanning and divides the review into the main parts of the process to be achieved: knowledge representation, geometric modelling, object recognition, relationship modelling and performance evaluation. The paper states that "methods and testbeds for evaluating algorithm performance have not been formalized" and calls for "...work to develop reference testbeds that span the use cases for as-built BIMs".

Hichri et al. (2013) summarises this landscape by concluding similarly to Tang et al. (2010) by saying that these approaches are satisfactory for simple planar geometry but for varied shapes many automation approaches would have to increase in complexity meaning that they would risk becoming bespoke to the scene being interpreted for reconstruction.

\section{AREAS UNDER INVESTIGATION}

The areas chosen to create the benchmark datasets are both sections of the UCL Chadwick Building; a late Victorian steelframed building with stone façades. This represents a typical historical building in London that has had several retrofits over the years to provide various spaces for the changing nature of activities within the UCL department housed inside; currently the Department of Civil, Environmental \& Geomatic Engineering.

The first area is a simple corridor section from the second floor of the building. The second area is a cluttered office from a modern retrofitted mezzanine.

\subsection{Basic Corridor}

This first area is a long repetitive corridor section from the second floor of the building. It roughly measures $1.4 \mathrm{~m}$ wide by $13 \mathrm{~m}$ long with a floor to ceiling height of $3 \mathrm{~m}$. The scene features doors off to offices at regular intervals and modern fluorescent strip lights standing proud of the ceiling. Poster mounting boards are fitted to the walls and at one end are two fire extinguishers.

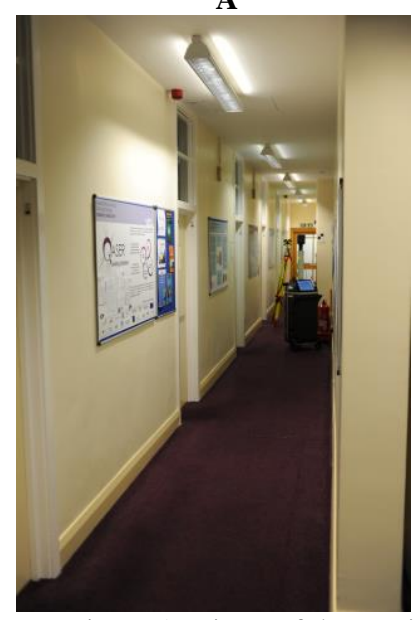

Figure 1. Views of the corridor as illustrated in Figure 2

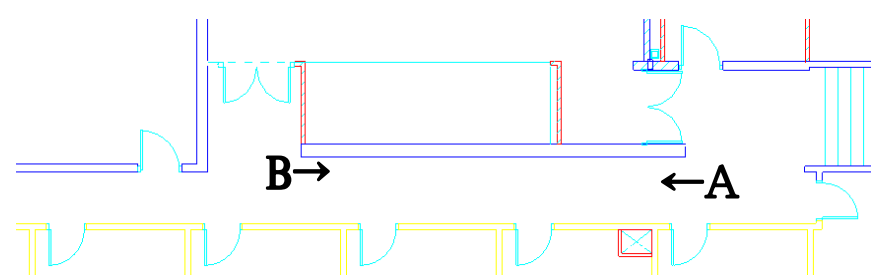

Figure 2. CAD plan of corridor and its surroundings

\subsection{Cluttered Office}

The second indoor environment is a standard office from the modern retrofitted mezzanine floor of the Chadwick Building. It roughly measures $5 \mathrm{~m}$ by $3 \mathrm{~m}$ with floor to ceiling height of $2.8 \mathrm{~m}$ at its highest point.

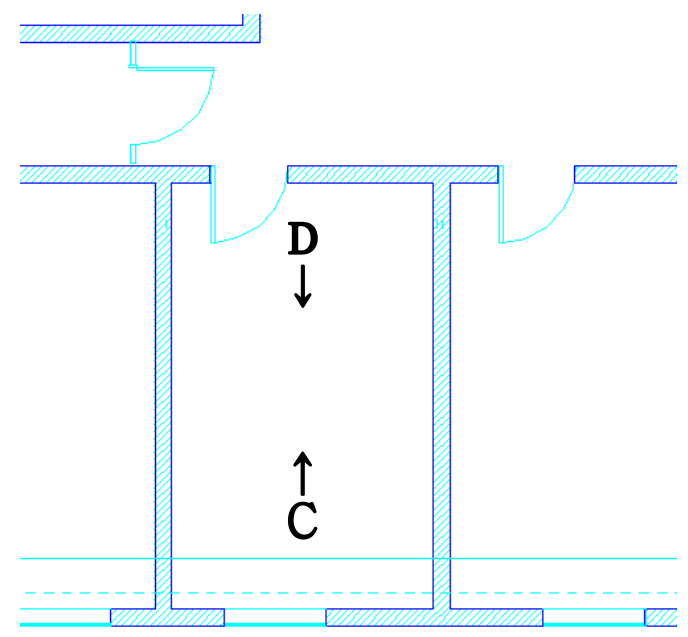

Figure 3. CAD plan of office and its surroundings

\section{C}

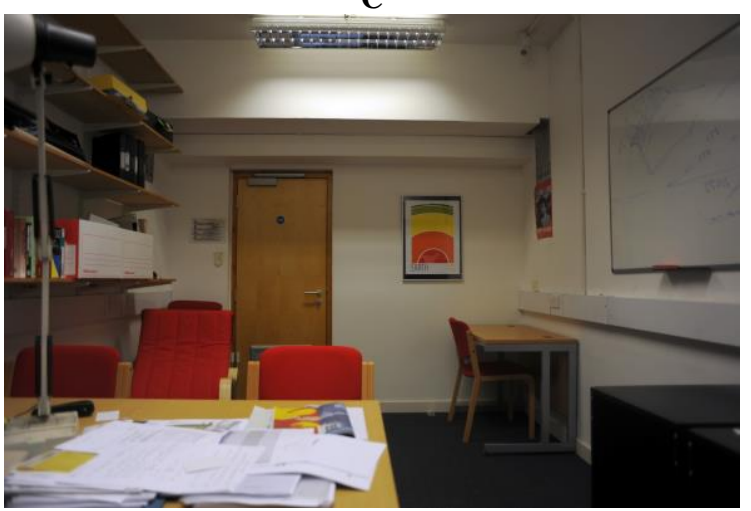

D

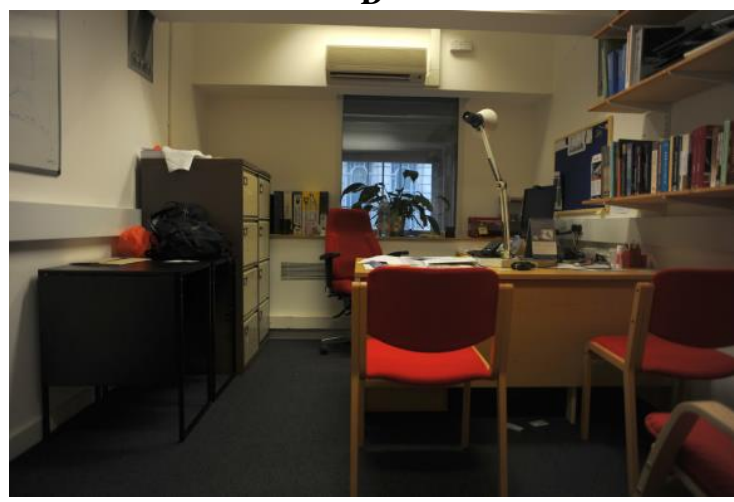

Figure 4. Views of the office as illustrated in Figure 3 
The environment contains many items of clutter that occlude the structural geometry of the room including filing cabinets, air conditioning unit, shelving, chairs and desks. Also there is a variable ceiling height due to supporting beams that have been boxed in with plasterboard with the top of the window recessed into a void. Although the structural steel is not visible, the steel hangers that support them are visible on each wall under each beam.

\section{BENCHMARK DATA FOR EVALUATION}

For each of the benchmark datasets, the capture process is described including the static scanning with a Faro Focus 3D laser scanner and indoor mobile mapping with a Viametris iMMS. These instruments represent the state of the art in both categories of system at time of writing. More can be read about their operation and fitness for purpose for indoor geometry capture in (Thomson et al., 2013) as well as test of manually created geometry.

The manual 'truth' model creation is also described with clarifications of what has been modelled and why. This model is created using the same standard process as done in industry to create the parametric model of an existing asset, thereby presenting a product of the status quo that is acceptable for further use by other participants in the BIM process. The specification used for the parametric modelling of both datasets is the freely available BIM Survey Specification produced by the UK-based surveying company Plowman Craven (Plowman Craven Limited, 2012). Both models were taken up to Level 3 as defined by this specification which requires basic families but not detailed and moveable objects to be created.

All the benchmark data described below in this section is freely available at: http://indoor-bench.github.io/indoor-bench

\subsection{Basic Corridor Data}

\subsubsection{Faro Focus 3D S}

Five scans were captured with the Faro Focus terrestrial laser scanner. The scan setting used was $1 / 8$ of full density at $4 \mathrm{x}$ quality. This provides a prospective density of $12 \mathrm{~mm}$ at $10 \mathrm{~m}$ with a full scan providing up to 10.9 million point measurements. The five scan setups were as shown in Figure 5 and were surveyed in using a Leica TS15 total station, as were their checkerboard targets.

\begin{tabular}{|c|r|r|r|r|}
\hline \multirow{2}{*}{ Scan No. } & \multicolumn{3}{|c|}{ Scan Position (metres) } & \multicolumn{1}{c|}{ Cropped } \\
\cline { 2 - 4 } & \multicolumn{1}{c|}{$\mathrm{X}$} & \multicolumn{1}{c|}{$\mathrm{Y}$} & \multicolumn{1}{c}{$\mathrm{Z}$} & \multicolumn{1}{c}{ Points } \\
\hline 000 & 4.814 & -8.115 & 0.229 & 254,159 \\
\hline 002 & 9.294 & -2.044 & 0.287 & 460,043 \\
\hline 004 & 4.814 & 4.281 & 0.193 & $10,222,459$ \\
\hline 006 & -3.825 & -3.377 & 0.236 & $9,761,475$ \\
\hline 008 & 0.000 & 0.000 & 0.000 & $10,677,978$ \\
\hline
\end{tabular}

Table 1. Scan positions and number of points in E57 benchmark

The scans were processed in Faro Scene 5.1 and a cropped section of the corridor exported as an E57 from CloudCompare (Girardeau-Montaut, 2012) with the extents illustrated in Figure 5. This means the cropped section includes a wall thickness to the adjoining lecture theatre in which scans 000 and 002 were captured. The pointclouds have had no further cleaning and so still contain the tripod setup positions of the total station.

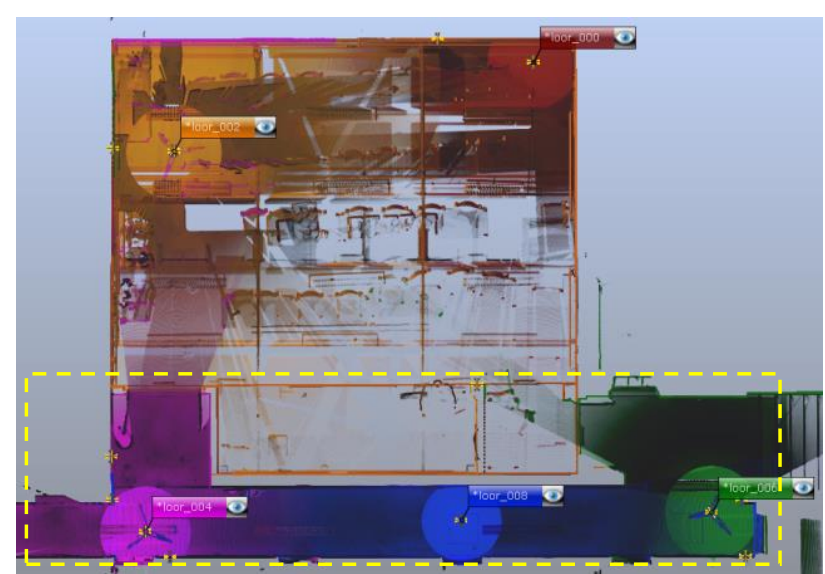

Figure 5. Faro scan positions after registration in Faro Scene; yellow dashed box indicates final cropped benchmark area

The global coordinate system origin was placed at the scan origin in scan 008 in the centre of the corridor. The coordinates of the scan positions relative to this are shown in Table 1 along with the number of points contributed from each setup to the final cropped dataset. Along with the coordinates, intensity data is also stored in the E57.

\subsubsection{Viametris iMMS}

The corridor was captured using a closed loop trajectory that started at one end of the corridor into the adjoining lecture theatre out the far end and looping back down the corridor to the start position as in Figure 6.

The data was processed in the Viametris PPIMMS software which improves the Simultaneous Location And Mapping (SLAM) solution that was computed by the instrument in real time to mitigate drift. The use of Hokuyo line scanners mean that the noise level in the resultant pointcloud is greater than that found in the Faro scans with a resultant accuracy of $\sim 3 \mathrm{~cm}$. It should be noted that the iMMS positions itself in 2D only and assumes a fixed height of the instrument in the third dimension, meaning artefacts can be seen in the data where the floor was not smooth.

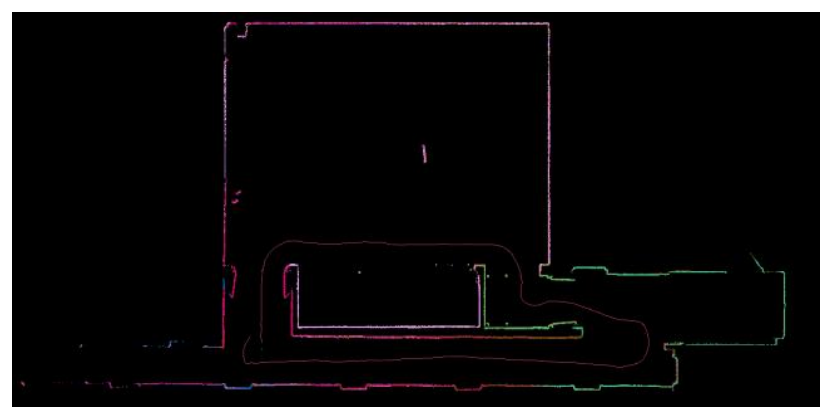

Figure 6. iMMS processed SLAM solution trajectory loop of corridor in Viametris PPIMMS software

Due to the arrangement of the line scanners and their blind spots, occlusions are present in the data where turns around corners prevent the other line scanner from filling in if the trajectory had been straight. The coordinate system of the Viametris data is defined by the starting position of the instrument becoming the origin.

The same area was cropped in CloudCompare as in the Faro data and exported to an E57 containing the coordinates and 
intensity data, leaving a mobile mapping dataset of 7.1 million points.

\subsubsection{Parametric Model}

To provide a form of verification ground truth, a manual model was created from the Faro scans following the workflow used currently by the UK survey industry. This involved loading the scans into Autodesk's Revit 2014. This meant that Revit performed a conversion into the Autodesk pointcloud format (.rcs).

As the model is an abstraction of the pointcloud, then certain assumptions are made by the user along the way to generate the geometry. In this case elements from the object library that comes with Revit 2014 were used, with the exception of the windows above the doors to the left of Figure 7 which are from the UK National BIM Library (NBS National BIM Library, 2014). All thicknesses are arbitrary, except for the separating wall between the lecture theatre and corridor as it was scanned from both sides.

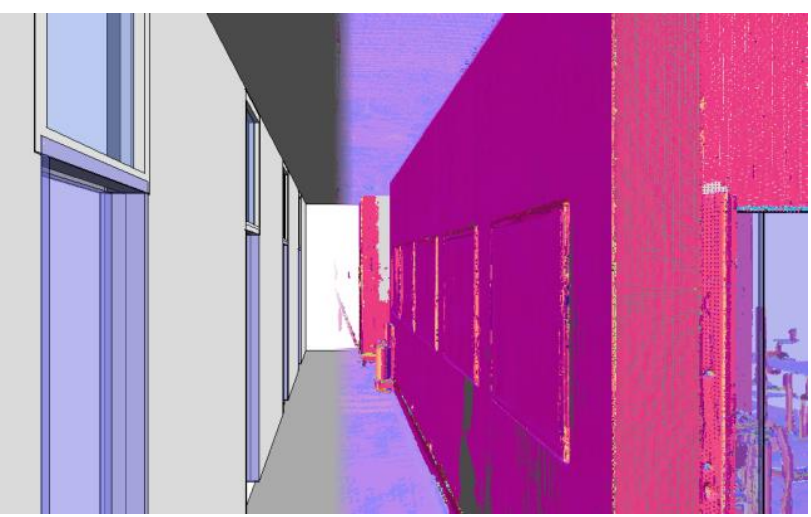

Figure 7. Hybrid showing pointcloud (coloured by normals) and resultant parametric model in a Revit 2014 3D view

\subsection{Cluttered Office Data}

\subsubsection{Faro Focus 3D S}

Severn scans were captured with the Faro Focus terrestrial laser scanner of office GM14. The scan setting used was $1 / 5$ of full density at $4 \mathrm{x}$ quality. This provides a prospective density of $8 \mathrm{~mm}$ at $10 \mathrm{~m}$ with a full scan providing up to 26.5 million point measurements. The seven scan setups were as shown in Figure 8 and, as with the corridor data, were surveyed in using a Leica TS15 total station, as were their checkerboard targets.

\begin{tabular}{|c|c|c|c|c|}
\hline \multirow{2}{*}{ Scan No. } & \multicolumn{3}{|c|}{ Scan Position (metres) } & \multirow{2}{*}{$\begin{array}{c}\text { Cropped } \\
\text { Points }\end{array}$} \\
\hline & $\mathrm{X}$ & $\mathrm{Y}$ & $\mathrm{Z}$ & \\
\hline GM13_001 & 11.124 & -16.552 & 4.413 & $2,164,250$ \\
\hline GM13 002 & 12.788 & -15.634 & 4.412 & $3,047,686$ \\
\hline GM14_002 & 13.181 & -19.433 & 4.402 & $24,885,862$ \\
\hline GM14_003 & 14.812 & -17.870 & 4.401 & $25,314,529$ \\
\hline GM15_001 & 16.884 & -20.470 & 4.415 & $2,301,605$ \\
\hline GM15_002 & 14.987 & -21.794 & 4.414 & $1,670,996$ \\
\hline GMC_006 & 19.693 & -17.779 & 4.501 & $1,922,178$ \\
\hline & & & Total: & $61,307,106$ \\
\hline
\end{tabular}

Table 2. Scan positions and number of points in E57 benchmark

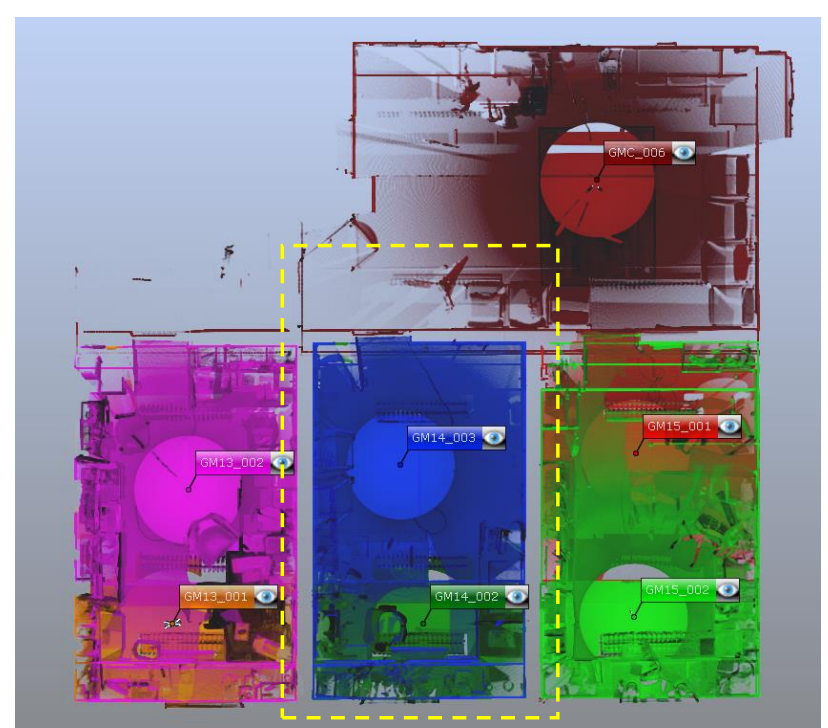

Figure 8. Faro scan positions after registration in Faro Scene; yellow dashed box indicates final cropped benchmark area

The scans were processed in Faro Scene 5.1 and a cropped section of the corridor exported as an E57 from CloudCompare with the extents illustrated in Figure 8. This means the cropped section includes wall thicknesses to the adjoining offices (GM13 \& GM15) as well as to a corridor (GMC). As with the Simple Corridor data, the pointclouds have had no further cleaning and still contains a tripod setup position as well as artefacts e.g. from the light reflectors.

The scans derive from a much larger surveyed dataset collected for the GreenBIM project (Backes et al., 2014) and therefore have a coordinate system whose origin is derived from the centre of the Chadwick Building at ground level. This means that the origin does not reside within the scope of any of the scans in this dataset. The coordinates of the scan positions are shown in Table 2 along with the number of points contributed from each setup to the final cropped dataset. Along with the coordinates, intensity data is also stored in the E57.

\subsubsection{Viametris iMMS}

The office was captured in a similar way to the corridor with a trajectory that starts outside the office, enters it and then returns to the starting position. However as the office has only one point of access, the loop is restricted to a fairly straight path with constrained turns. An advantage of this type of trajectory is that occlusions caused by the blind spots of the scanners are minimised as most areas get captured by a scanner in each orientation.

As with the corridor data this Viametris pointcloud of the office has its origin at the start position of the instrument.

The same area was cropped in CloudCompare as in the Faro data and exported to an E57 file containing the coordinates and intensity data, leaving a mobile mapping dataset of 3.0 million points. 


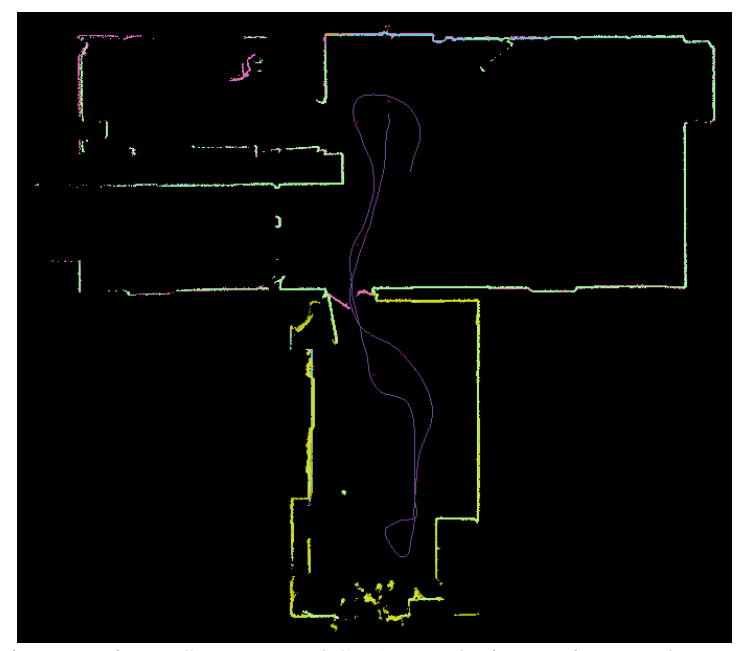

Figure 9. iMMS processed SLAM solution trajectory loop of office in Viametris PPIMMS software

\subsubsection{Parametric Model}

The model was manually built to the same specification as that of the corridor but to a slightly higher level of detail. All of the structure, door and window of the office model are built with stock Revit elements. Prominent fixed features were included from outside the stock Revit 2014 object library with the air conditioning and strip lights coming from Autodesk Seek respectively (Autodesk/Mitsubishi Electric, 2013) and (Autodesk/Cooper Lighting, 2013).

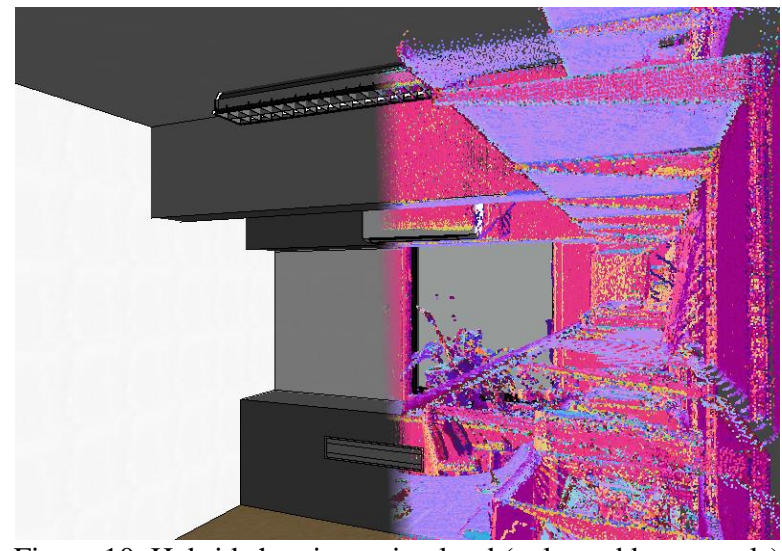

Figure 10. Hybrid showing pointcloud (coloured by normals) and resultant parametric model in a Revit 2014 3D view

\section{INITIAL RECONSTRUCTION RESULTS}

In this section, an initial test of the benchmark datasets is presented to provide a guide of how the authors consider the reconstructed geometry can be assessed against them. This test made use of the prominent commercial tool for semi-automating simple geometry reconstruction for BIM: Scan to BIM (IMAGINiT Technologies, 2014). It should be noted the name of the software is a misnomer as what it provides is the parametric geometry necessary for the BIM process rather than BIM itself.

Scan to BIM operates as a Revit plugin that embeds itself into the Revit toolbar and for wall geometry reconstruction uses a semi-automated region growing approach. This works with the user picking three points to define the plane of the wall which is then expanded to the extents of the pointcloud within a user- defined tolerance. The user then has the option to create a wall of a type from the project library which follows the orthogonal constraints of the Revit environment or a mass wall which can deform. For this test the former wall type was chosen. This is illustrated below in Figure 11 with the tolerances used for both datasets of $2.5 \mathrm{~cm}$ planar tolerance and $3 \mathrm{~cm}$ closeness tolerance.

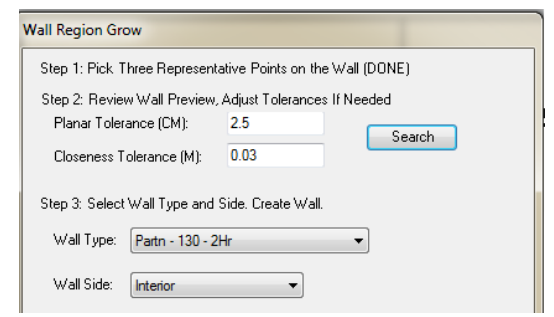

Figure 11. Scan to BIM Wall Creation Settings

\subsection{Basic Corridor}

To assess the performance of the semi-automatically fitted walls created by Scan to BIM, a series of common measurements were taken and compared back to the manually-made reference to see the success or detriment of this implementation.

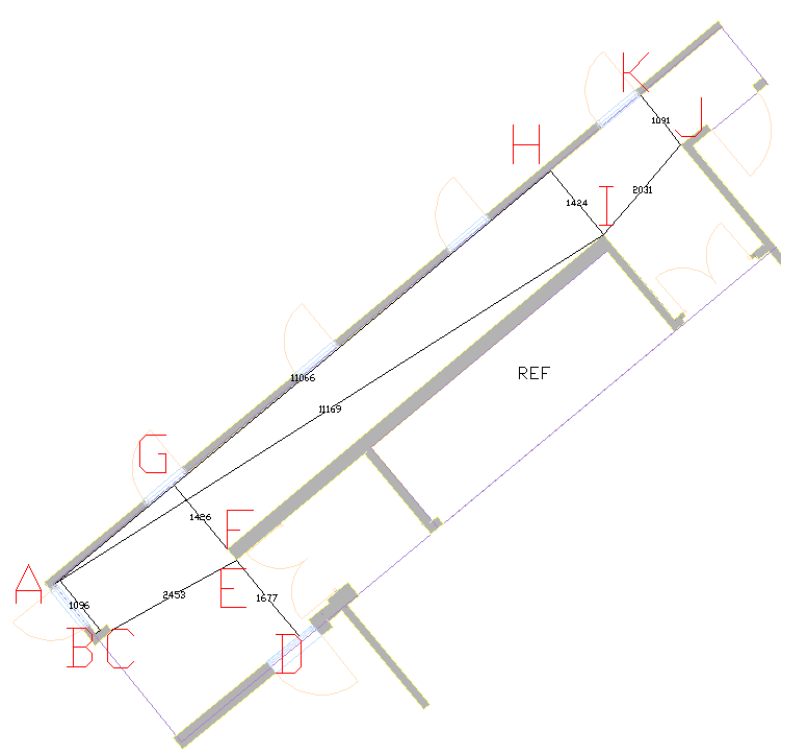

Figure 12. Plan view of reference data and placement of common measurements taken for all datasets

\begin{tabular}{|c|c|c|c|}
\cline { 2 - 4 } \multicolumn{1}{c|}{} & $\begin{array}{c}\text { Measurements } \\
(\mathrm{mm})\end{array}$ & \multicolumn{2}{c|}{$\begin{array}{c}\text { Relative difference from } \\
\text { reference data }(\mathrm{mm})\end{array}$} \\
\hline $\begin{array}{c}\text { Corridor } \\
\text { Geometry }\end{array}$ & Reference & StB Faro & $\begin{array}{c}\text { StB } \\
\text { Viametris }\end{array}$ \\
\hline A-B & 1096 & -36 & -6 \\
\hline A-H & 11066 & +37 & +70 \\
\hline A-I & 11169 & +37 & +59 \\
\hline C-E & 2453 & -5 & -1 \\
\hline D-E & 1677 & -102 & +5 \\
\hline F-G & 1426 & +4 & +22 \\
\hline H-I & 1424 & +5 & -4 \\
\hline I-J & 2031 & -5 & -57 \\
\hline J-K & 1091 & -8 & -84 \\
\hline $\begin{array}{c}\text { From Reference: } \\
\text { Mean deviation }\end{array}$ & - & -8 & 0 \\
\hline St. Deviation & - & 42 & 49 \\
\hline
\end{tabular}

Table 3. Comparison measurements between the corridor reference geometry and that created from Scan to BIM (StB) 
Measurements G-F, E-D, H-I and J-K are created perpendicular to the wall line of F-I.

As shown in Table 3 there is fairly good agreement of a few $\mathrm{mm}$ between wall-to-wall measurements of the reference model and Faro-derived walls. Overall the short measurements in Figure 12 are within $4 \mathrm{~cm}$ of the reference. The outliers are D-E and I-J, $\mathrm{J}-\mathrm{K}$. The $10 \mathrm{~cm}$ deviation between $\mathrm{D}-\mathrm{E}$ is likely due to the wall mounted poster board on the wall defined at $\mathrm{D}$ skewing the fit. The wall at D has been well captured by the Faro scan at that end of the corridor as opposed to in the Viametris data where it seems to have had less of an influence over the fit. Removing this outlier brings the mean to around $3 \mathrm{~mm}$ deviation. The deviations of I-J and $\mathrm{J}-\mathrm{K}$ in the Viametris derived geometry are due to poor coverage in the pointcloud caused by the scanners' blind spot positions when the instrument turned.

\subsection{Cluttered Office}

The same process was carried out with the office data, producing common measurements across the model to see the performance of the Scan to BIM software. The measurements in Figure 13 are to the corners of the room but are illustrated with leader tails on the dimension lines for clarity.

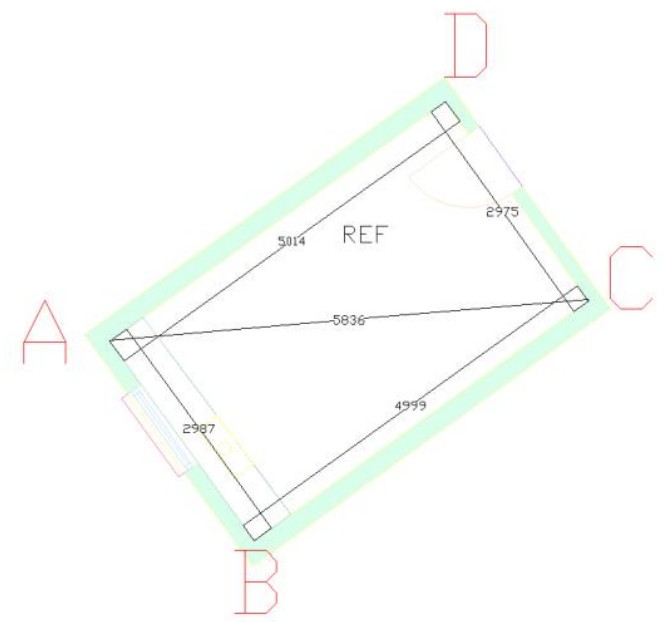

Figure 13. Plan view of reference data and placement of common measurements taken for all datasets

\begin{tabular}{|c|c|c|c|}
\cline { 2 - 4 } \multicolumn{1}{c|}{} & $\begin{array}{c}\text { Measurements } \\
(\mathrm{mm})\end{array}$ & \multicolumn{2}{c|}{$\begin{array}{c}\text { Relative difference from } \\
\text { reference data }(\mathrm{mm})\end{array}$} \\
\hline Office Geometry & Reference & StB Faro & $\begin{array}{c}\text { StB } \\
\text { Viametris }\end{array}$ \\
\hline A-B & 2987 & -8 & -49 \\
\hline B-C & 4999 & -3 & -43 \\
\hline C-D & 2975 & -4 & -11 \\
\hline D-A & 5014 & -12 & -20 \\
\hline A-C & 5836 & -9 & -29 \\
\hline $\begin{array}{c}\text { From Reference: } \\
\text { Mean deviation }\end{array}$ & - & -7 & -30 \\
\hline St. Deviation & - & 4 & 16 \\
\hline
\end{tabular}

Table 4. Comparison measurements between the office reference geometry and that from Scan to BIM (StB)

The datasets for the office, although cluttered, provide results shown in Table 4 more in line with expectations than the previous corridor data. The fitted wall geometry from the Faro data is in the order of a few $\mathrm{mm}$, with that from the Viametris around $3 \mathrm{~cm}$. These results tally with the behaviour expected based on the performance and related modelling ambiguity from these instruments.

In both cases the semi-automated geometry from Scan to BIM is within the medium tolerance specified by UK survey companies with the Faro derived walls fulfilling the high tolerance of 15mm (Plowman Craven Limited, 2012).

\section{DISCUSSION}

The tests in the previous section with Scan to BIM demonstrate what is possible currently with commercial software for automating parametric geometry creation. Between both scenes there is a difference in the reconstructed geometry's quality, with the cluttered office more successful overall than the corridor.

Clutter has an effect in the office data set but not as much as expected. This could be due to the enclosed nature of the space and scan settings, meaning a dense point spacing was achieved on the parts of the walls that were captured. In terms of performance the deviations were within a few $\mathrm{cm}$ at most and in most cases were within industry specifications for model tolerance.

Based on the accuracy of the manually created Revit models from the same instruments in (Thomson et al., 2013) the simple walls reconstructed here compare favourably, especially when the reduction of user input is factored in.

Overall this is promising but is only the reconstruction of the simplest elements: the walls. There exist many other features in the two scenes (floor, ceiling, air conditioning unit, beams, etc.) that could potentially be modelled with reduced user interaction.

\section{CONCLUSIONS}

The literature indicates that automation to some degree may aid this reconstruction and quite a few techniques have been presented. As shown by this initial paper, one commercial application of semi-automation is effective with simple wall geometry. There exist questions around implementation and validation of the geometry created. With 25 years of research having not achieved full automation of geometry extraction then semi-automated approaches as used by current commercial software tools in this space appears to be the favoured approach.

Current laser scanning technology easily allows a 'capture all' mentality. Thanks to improvements in capture rate, and with indoor mobile mapping, this trend will continue into the foreseeable future. This creates a new paradigm on the geometry reconstruction side of modelling where fast generation of models is crucial to keep the workflow optimal, especially in a BIM context. Therefore the pointcloud remains as a complex representation with good visuals and high level of geometric detail but non-existent level of information overall as it is just 'dumb' points requiring interpretation.

This is not good for BIM which requires a high level of geometric intelligence in the form of parametrics and semantics. As shown here there has been some progress in commercial software with a semi-automated process and tied with the increasing approaches to the problem of indoor reconstruction in literature shows the significance of the topic. That said, few 
approaches show the creation of the parametric geometry needed for BIM which involves larger questions about levels of detail of representation, accuracy and semantic completeness.

Certainly in the UK, BIM is of increasing importance. With the majority of buildings that exist now still forecast to exist in 2050 (UK Green Building Council, 2013) then models of existing assets and more optimal ways of producing them will only become more necessary.

Lastly the authors invite the research community to participate by taking the benchmark datasets and using them to help gauge the improvements and success of different techniques that could lead to better, more efficient 3D geometry extraction for the indoor environment.

\subsection{Future Work}

Although it is felt these datasets provide adequate initial scenes for testing, the lack of well-known initial dimensions in the real world means the comparison to a 'truth' is from one abstracted set of measurements to another. The only way to have a definite truth at the beginning of the process is with synthetic data generated from a known 3D model. Therefore it is envisaged that this would be the next dataset that would be added to the benchmark alongside the real world data presented in this paper.

There is also the potential to expand the dataset with other representative scenes that are prevalent in buildings that require a model of existing conditions for BIM, e.g. plant rooms, large open-plan spaces, etc.

\section{REFERENCES}

Adan, A., Huber, D., 2011. 3D Reconstruction of Interior Wall Surfaces under Occlusion and Clutter, in: 2011 International Conference on 3D Imaging, Modeling, Processing, Visualization and Transmission. IEEE, pp. 275-281. doi:10.1109/3DIMPVT.2011.42

Autodesk/Cooper Lighting, 2013. Autodesk Seek: Cooper Lighting: Metalux ${ }^{\mathrm{TM}}$ 2PGAX Series Luminaire, 4" Precision Cell Louver Into A 6-3/4" Deep Para-Contoured Fixture Housing. URL: http://seek.autodesk.com/product/latest/agg/cooperlighting/CooperLighting/CooperLightingPara2PGAX (accessed 08.05.14).

Autodesk/Mitsubishi Electric, 2013. Autodesk Seek: Mitsubishi Electric: Wall Mounted, MSY Series Air Conditioner. URL: http://seek.autodesk.com/product/latest/agg/mitsubishielectric/Mitsubis hi-Electric/MitsubishiElectric019 (accessed 08.05.14).

Backes, D., Thomson, C., Malki-Ephshtein, L., Boehm, J., 2014. Chadwick GreenBIM: Advancing Operational Understanding of Historical Buildings with BIM to Support Sustainable Use, in: BSO 2014 Proceedings. IBPSA-England, London, UK, p. (In Press).

Barnea, S., Filin, S., 2013. Segmentation of terrestrial laser scanning data using geometry and image information. ISPRS J. Photogramm. Remote Sens. 76, 33-48. doi:10.1016/j.isprsjprs.2012.05.001

Budroni, A., Boehm, J., 2010. Automated 3D Reconstruction of Interiors from Point Clouds. Int. J. Archit. Comput. 8, 55-73. doi:10.1260/1478-0771.8.1.55

Girardeau-Montaut, D., 2012. CloudCompare-Open Source project. OpenSource Proj. URL: http://www.danielgm.net/cc/ (accessed 30.06.13).

Hichri, N., Stefani, C., Luca, L. De, Veron, P., 2013. REVIEW OF THE «AS-BUILT BIM » APPROACHES, in: Boehm, J., Remondino,
F., Kersten, T., Fuse, T., Gonzalez-Aguilera, D. (Eds.), 3D-ARCH 2013 - 3D Virtual Reconstruction and Visualization of Complex Architectures. International Society for Photogrammetry and Remote Sensing, Trento, Italy, pp. 107-112.

IMAGINiT Technologies, 2014. Scan to BIM. URL: http://www.imaginit.com/software-solutions/imaginit-products/scan-tobim (accessed 11.05.14).

Kawashima, K., Kanai, S., Date, H., 2011. AUTOMATIC RECOGNITION OF PIPING SYSTEM FROM LARGE-SCALE TERRESTRIAL LASER SCAN DATA. ISPRS - Int. Arch. Photogramm. Remote Sens. Spat. Inf. Sci. XXXVIII-5/, 283-288. doi:10.5194/isprsarchives-XXXVIII-5-W12-283-2011

Nagel, C., Stadler, A., Kolbe, T.H., 2009. Conceptual requirements for the automatic reconstruction of building information models from uninterpreted 3d models, in: Kolbe, T.H., Zhang, H., Zlatanova, S. (Eds.), GeoWeb 2009 Academic Track - Cityscapes. Vancouver, Canada, pp. 46-53. doi:10.1.1.150.9821

NBS National BIM Library, 2014. Window for flexible opening sizes. URL: http://www.nationalbimlibrary.com/generic/window-for-flexibleopening-sizes (accessed 08.05.14).

Oesau, S., Lafarge, F., Alliez, P., 2014. Indoor scene reconstruction using feature sensitive primitive extraction and graph-cut. ISPRS J. Photogramm. Remote Sens. 90, 68-82. doi:10.1016/j.isprsjprs.2014.02.004

Plowman Craven Limited, 2012. PCL BIM Survey Specification v2.0.3. Harpenden, UK.

$\mathrm{Pu}, \mathrm{S}$., Vosselman, G., 2009. Knowledge based reconstruction of building models from terrestrial laser scanning data. ISPRS J. Photogramm. Remote Sens. 64, 575-584. doi:10.1016/j.isprsjprs.2009.04.001

Rajala, M., Penttilä, H., 2006. Testing 3D Building Modelling Framework in Building Renovation, in: Bourdakis, V., Charitos, D. (Eds.), Communicating Space(s), Proceedings of the 24th Education and Research in Computer Aided Architectural Design in Europe Conference. Volos, Greece, pp. 268-275.

Schmittwilken, J., Plümer, L., 2010. Model-based reconstruction and classification of facade parts in 3D point clouds. Int. Arch. Photogramm. Remote Sens. Spat. Inf. Sci. 38, 269-274.

Tang, P., Huber, D., Akinci, B., Lipman, R., Lytle, A., 2010. Automatic reconstruction of as-built building information models from laserscanned point clouds: A review of related techniques. Autom. Constr. 19, 829-843. doi:10.1016/j.autcon.2010.06.007

Tao, C.V., 2005. 3D Data Acquision and Object Reconstruction for AEC/CAD, in: Zlatanova, S., Prosperi, D. (Eds.), Large-Scale 3D Data Integration: Challenges and Opportunities. CRC Press, Boca Raton, Florida, pp. 39-56. doi:10.1201/9781420036282

Thomson, C., Apostolopoulos, G., Backes, D., Boehm, J., 2013. Mobile Laser Scanning for Indoor Modelling. ISPRS Ann. Photogramm. Remote Sens. Spat. Inf. Sci. II-5/W2, 289-293. doi:10.5194/isprsannals-II-5-W2-289-2013

UK Green Building Council, 2013. Retrofit. URL: http://www.ukgbc.org/content/retrofit (accessed 20.04.13). 